\title{
Attitude of dental interns with malocclusion towards seeking orthodontic treatment
}

\author{
M Sharmila $^{1 *}$, P. Rajakumar ${ }^{2}$, U. Vivekanandan ${ }^{3}$, R. Shivani ${ }^{4}$, S. Gopalakrishnan ${ }^{5}$, Gomathi G.D ${ }^{6}$ \\ ${ }^{1,6}$ Post Graduate, ${ }^{2}$ Reader, ${ }^{3}$ Senior Lecturer, ${ }^{4}$ Assistant Professor, ${ }^{5}$ Professor, ${ }^{1-3}$ Dept. of Orthodontics, ${ }^{4}$ Dept. of Dentistry, \\ ${ }^{5,6}$ Dept. of Periodontics, ${ }^{\mathbf{1 - 3 , 5}, 6}$ Thai Moogambigai Dental College and Hospital, Chennai, Tamil Nadu, ${ }^{4}$ Madha Medical \\ College and Research Institute, Thandalam, Tamil Nadu, India
}

*Corresponding Author: Sharmila M

Email: sharmisharmila84@gmail.com

\begin{abstract}
Aim: To determine the attitude of dental interns with malocclusion towards seeking orthodontic treatment.

Materials and Methods: 50 dental interns with malocclusion in seek of orthodontic treatment participated in the study. They were given 10 polar questions relating to their concern about seeking orthodontic treatment, answers were recorded and statistical analysis was carried out.

Results: Overall the percentage of positive responses from the dental interns with malocclusion towards seeking orthodontic treatment is $61 \%$ and the percentage of negative responses is $39 \%$. The negative responses are due to two reasons. One is $58 \%$ feared about the quality of the treatment and the other is $60 \%$ concerned about the long treatment durations.

Conclusion: It is obvious from the study that most of the dental interns are completely aware about orthodontic treatment and their outcomes. Also, most of the dental students besides knowing the demerits of the orthodontic treatment are not found to be apprehensive to undertake the treatment and showed a positive approach towards it.
\end{abstract}

Keywords: Malocclusion, Orthodontic treatment, Dental students, Anxiety.

\section{Introduction}

Malocclusion is defined as any deviation from the norm of the arrangement of the teeth and occurs commonly among various populations. ${ }^{1,2}$ While considered non-life threatening, malocclusion may cause altered functions (mastication, speech) and poor dentofacial-esthetics that reduce the quality of life of affected subjects including social and functional limitations. ${ }^{3}$ Malocclusion has also been associated with the development of periodontal disease, although not a direct aetiology. ${ }^{4}$ As malocclusion is highly affects the aesthetics and oral health, treatment for such problem is needed. The awareness about orthodontic treatment is highly spread to the public and the field of orthodontics is growing greatly with various advancements in treatment options.

Orthodontic treatment has its own pros and cons. Though the orthodontic treatment ends up creating beautiful smiles and immense satisfaction to the patient by changing their aesthetics, psychological status of social wellbeing and their lifestyle, it has few disadvantages too. Pain, root resorption, weight loss, periodontal disease, proneness for dental caries, high cost, temperomandibular joint dysfunction, relapse tendency, compromised aesthetics during the treatment, long time treatment procedures are few drawbacks of orthodontic treatment ${ }^{5}$. As dental interns are well aware of the orthodontic treatment benefits and adverse effects, this study is done to determine their attitude towards seeking orthodontic treatment.

\section{Materials and Methods}

The study included 50 dental interns with malocclusions who approached for orthodontic treatment. A questionnaire was prepared containing 10 polar questions relating to their concern about seeking orthodontic treatment despite of knowing the drawbacks of the treatment. This questionnaire was given to those 50 dental interns and recorded the answers.

\section{Results}

The questionnaire and the statistical data obtained are as follows 


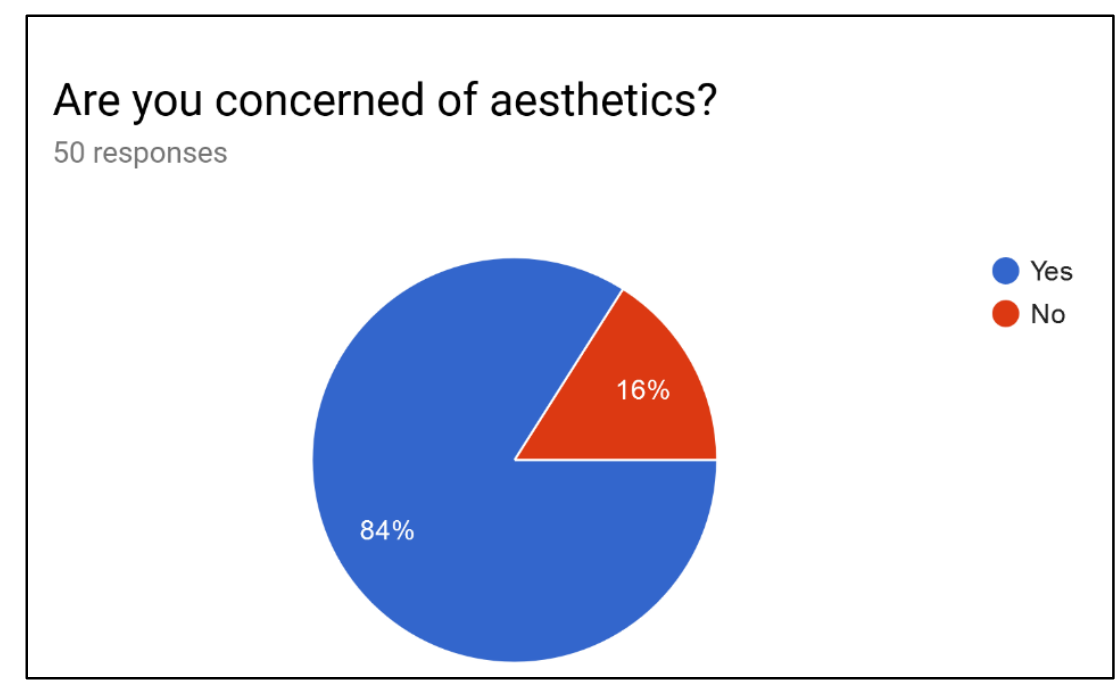

Out of 50 responses about concerning aesthetics, $84 \%$ are concerned about their esthetics and $16 \%$ are not.

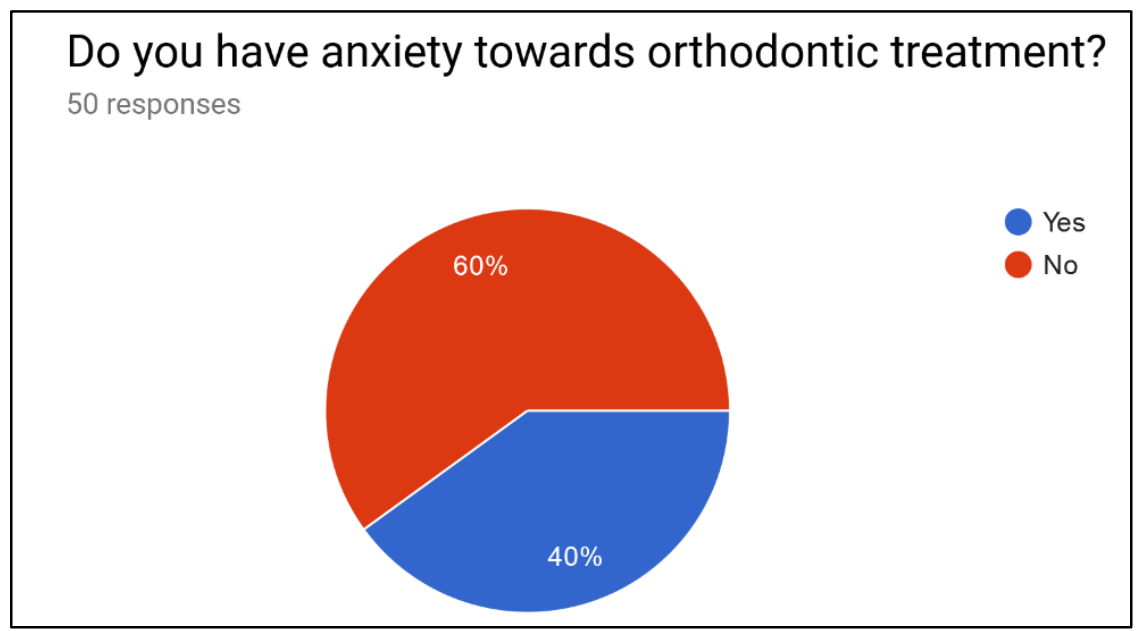

Out of 50 responses to anxiety towards the treatment, $60 \%$ of were anxious towards the treatment and $40 \%$ were interested for the treatment.

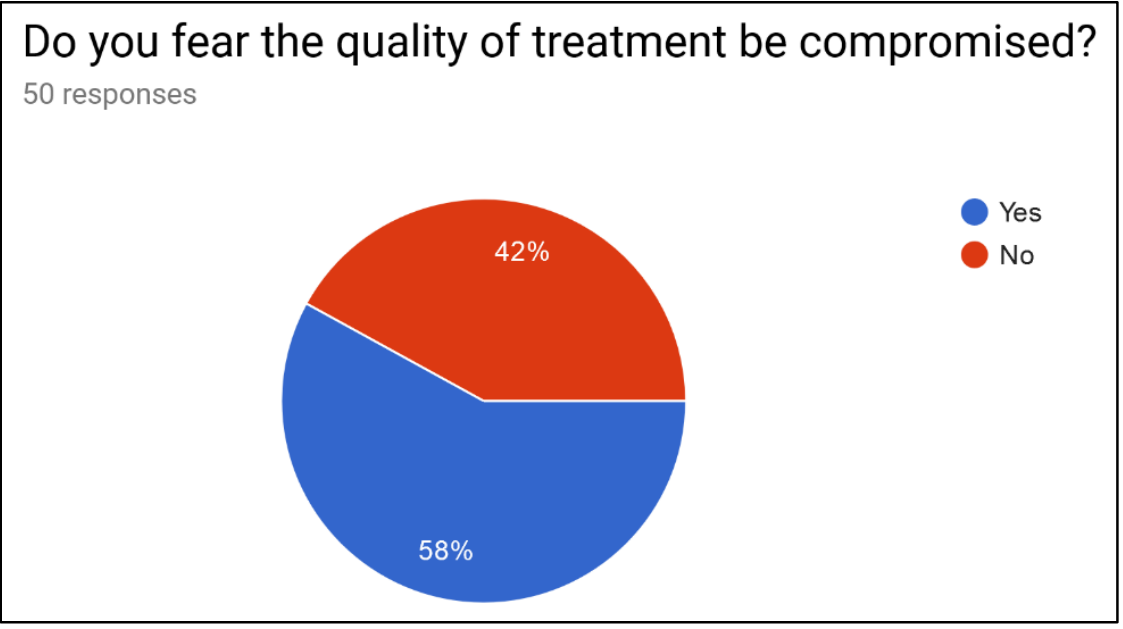

Out of 50 responses regarding fear on quality of treatment, 58\% of students were scared to take up the treatment and $42 \%$ have trust towards the orthodontic procedure. 
Is there a concernof your education /studies being affected by orthodontictreatment?

50 responses

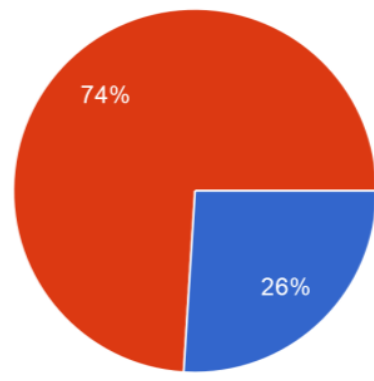

Yes

No

Out of 50 responses regarding the concern on education, $74 \%$ feel their studies will not be affected due to the orthodontic treatment and $26 \%$ were not comfortable to take up treatment.

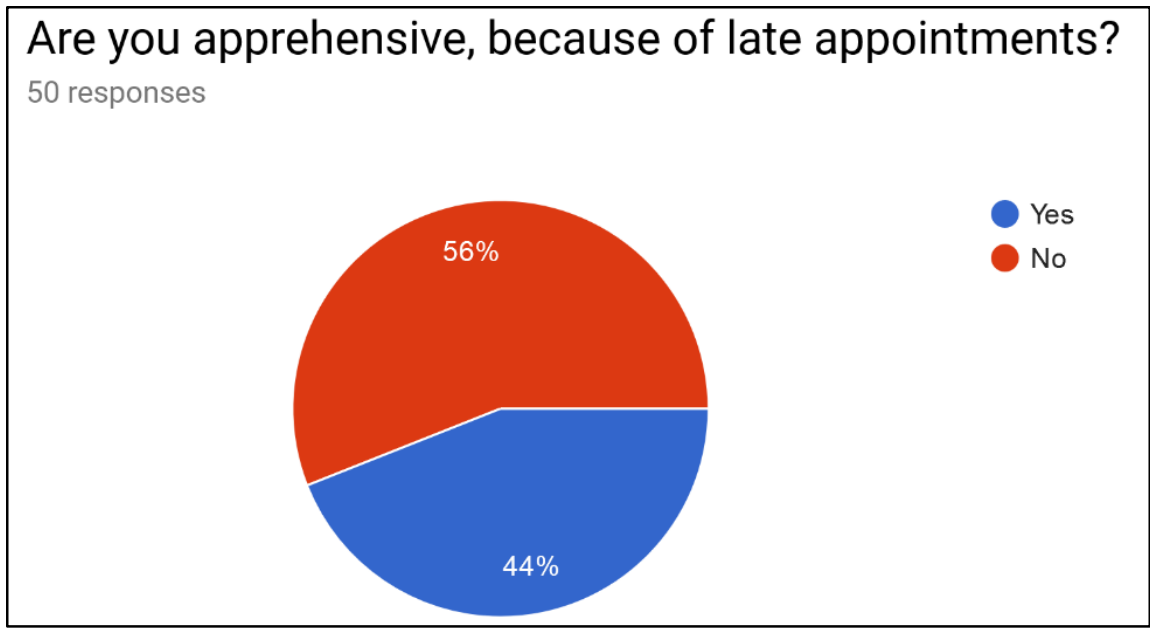

Out of 50 response regarding late appointments $44 \%$ of students were apprehensive and $56 \%$ of students were confident to take up the treatment.

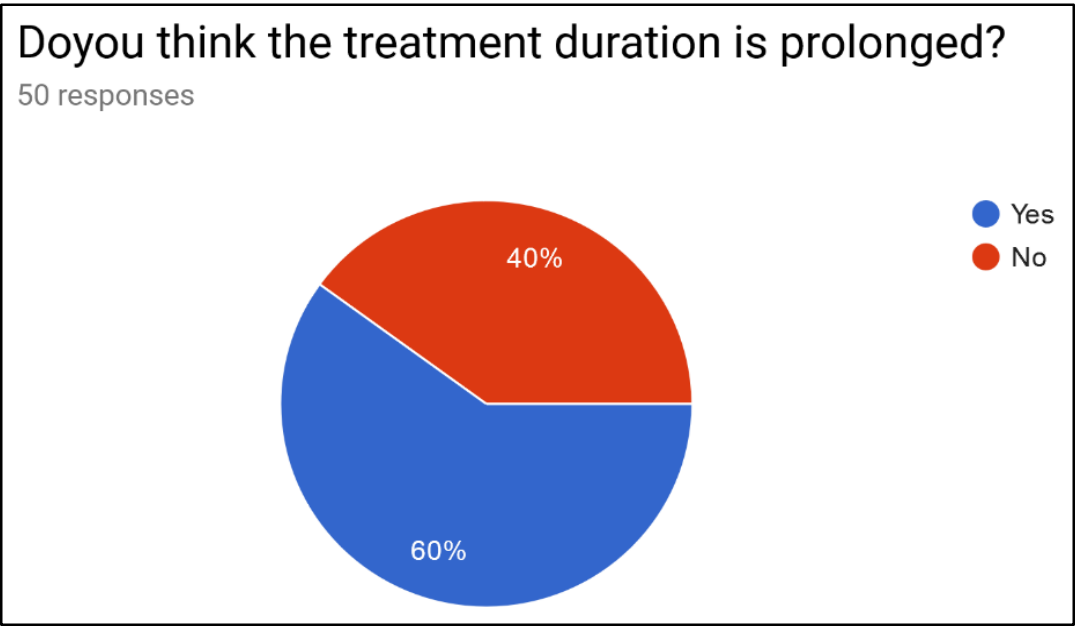

Out of 50 responses pertaining to the duration of treatment, $60 \%$ found it to be long and $40 \%$ are not concerned about the long term procedures. 


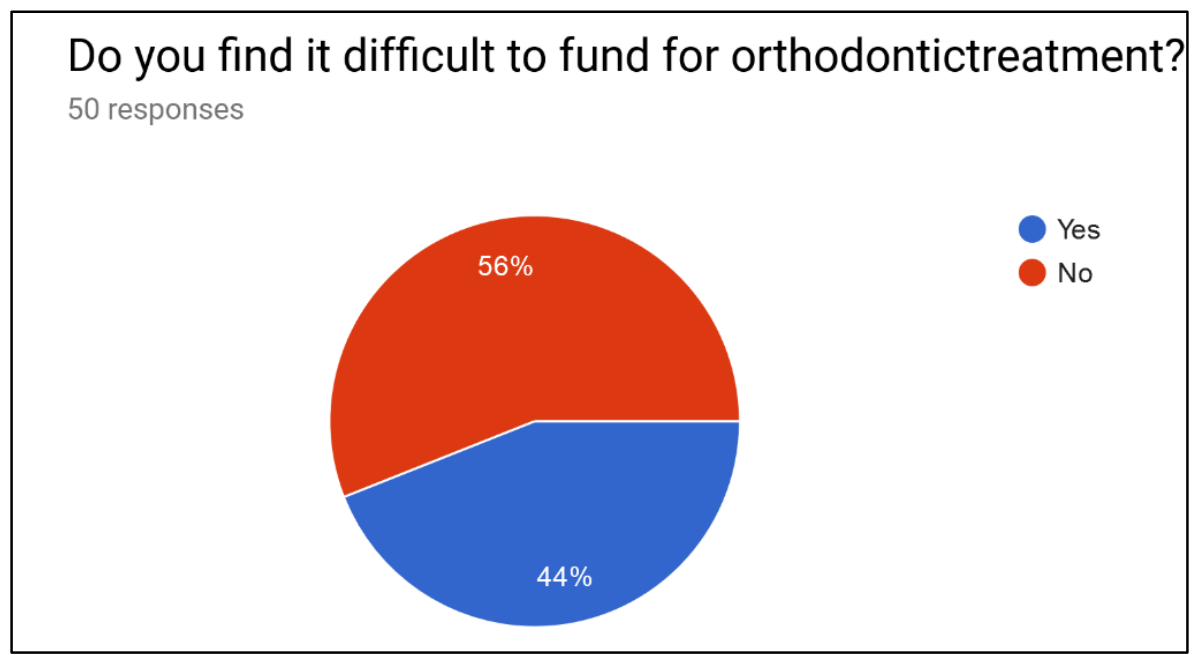

Out of 50 responses regarding funding the treatment, $56 \%$ didn't feel any difficulty in funding treatment and $44 \%$ felt treatment is quite expensive

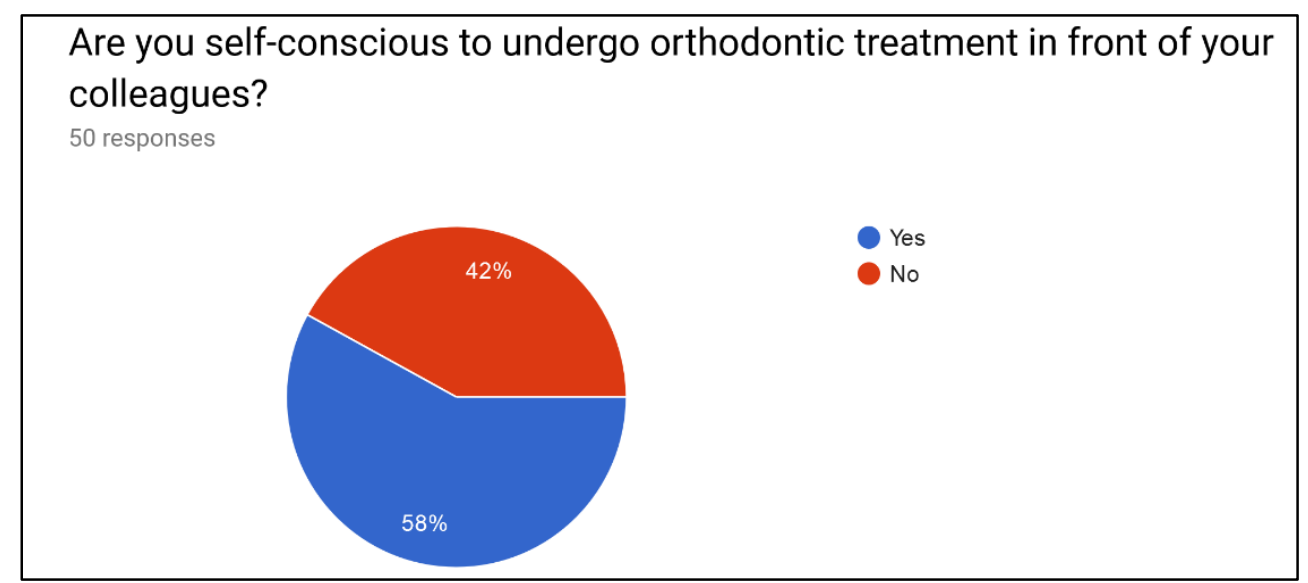

Out of 50 responses pertaining to self-consciousness of undergoing treatment in front of their colleague, $58 \%$ are more concerned to it and $42 \%$ are comfortable to take up the treatment.

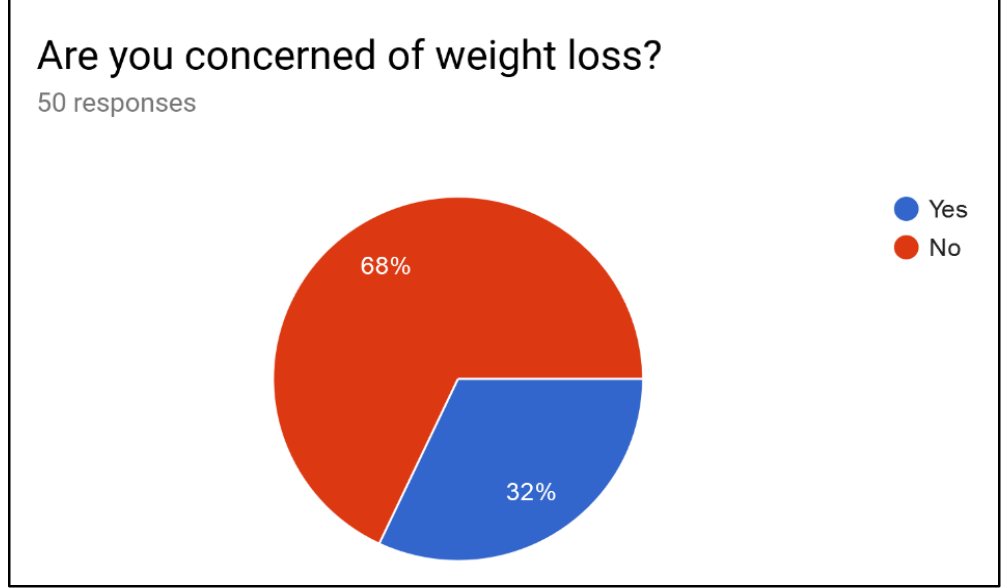

Out of 50 responses regarding weight loss, $68 \%$ are not concerned about their weight during the treatment and $32 \%$ are concerned about reduction in their weight. 


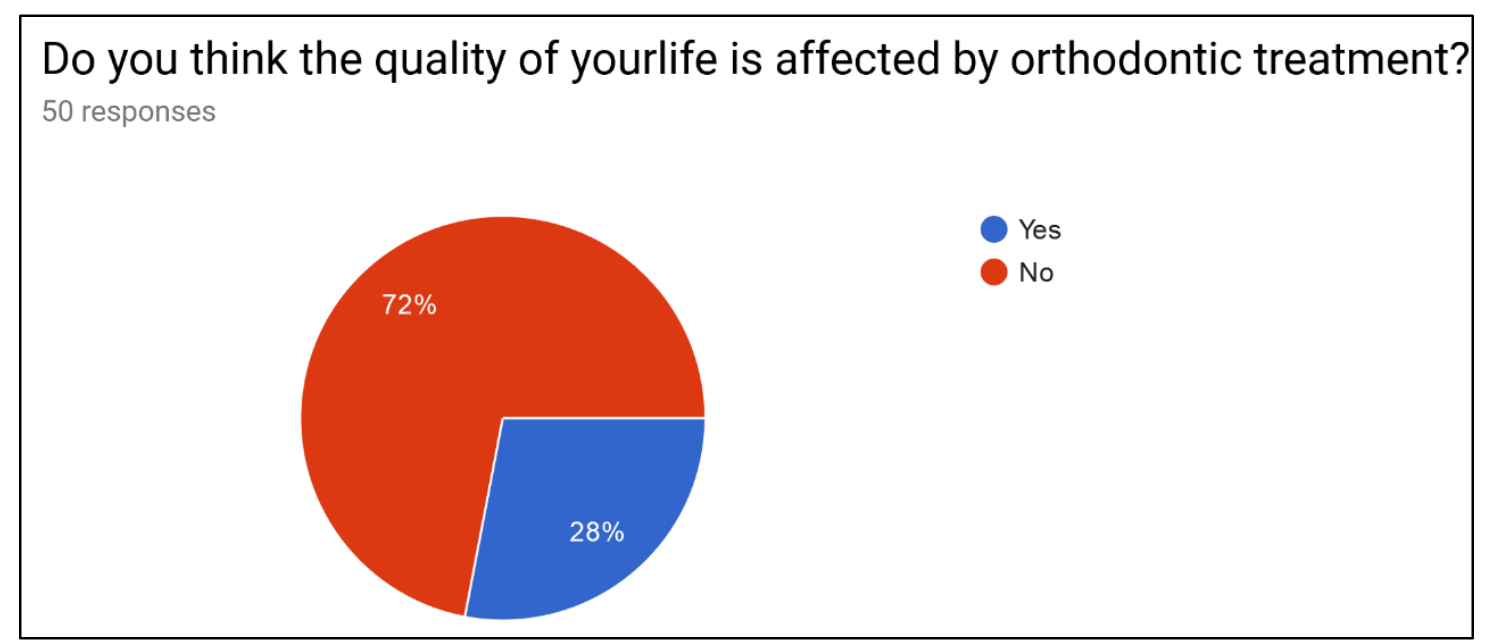

Out of 50 response regarding the quality of life, $72 \%$ cheerful to seek the orthodontic treatment and $28 \%$ feel treatment will have impact on their quality of life.

Overall the percentage of positive responses from the dental interns with malocclusion towards seeking orthodontic treatment is $61 \%$ and the percentage of negative responses is $39 \%$.

\section{Discussion}

Malocclusion, a universal dental problem creates not only oral health issues but also affecting the psychological well being of a person. As the esthetic concern of an individual and malocclusion develops during the same ages, the teenagers and young adults more likely seek orthodontic treatment. Dental interns in the same age group, studied orthodontics as a subject and are well aware of the advantages and disadvantages of the treatment. 'Doctors make the worst patients' is a famous quote which means that it is difficult to advise people on subjects that they are experts on. As a result, in order to determine the attitude of dental interns with malocclusion towards seeking orthodontic treatment, this study has been done. The results of the study showed $61 \%$ positive response from the dental interns towards seeking orthodontic treatment and 39\% negative response for the same.

In Indian context, few authors did similar studies with undergraduate dental students and assessed their attitude towards orthodontic treatment. Baswaraj et al conducted a study with 230 undergraduate dental students, to assess dental students' perception of orthodontic treatment and the relationship between physical appearance and the impact of such deviation on self-esteem. They found that $75 \%$ of the students were aware of their dental esthetics and $31 \%$ had a strong positive attitude toward it. ${ }^{6}$ Riya Agrawal studied the knowledge, attitude and perception of orthodontics treatment among 300 undergraduate dental students and found that $30 \%$ had a strong positive attitude towards orthodontic treatment. ${ }^{7}$ Disha D Kandi studied 215 dental students with malocclusion and concluded the reasons for their negative response towards orthodontic treatment. Among 215 dental students, $28.17 \%$ students believe orthodontic treatment as long duration treatment, 26.23\% students have subjective fear about treatment, $21.78 \%$ avoid it because of pain during treatment, $13.36 \%$ of students neglected orthodontic treatment, $6.43 \%$ students feels orthodontic treatment expensive, $3.46 \%$ students avoid it because of fear of relapse. ${ }^{8}$ In our study, it has been found that, $58 \%$ feared about the quality of the treatment and $60 \%$ concerned about the long treatment durations. These two factors are considered negative about the orthodontic treatment by the dental interns participated in our study. Otherwise, they showed a overall positive response $(61 \%)$ towards the orthodontic treatment.

\section{Conclusion}

Our study breaks the stereotype of considering 'doctors make the worst patients' as it concluded an overall positive response from the dental interns, despite of knowing the demerits in orthodontic treatment. However, this study is a pilot effort to know the attitude of the dental interns towards seeking orthodontic treatment. This positive attitude shows that the dental interns consider orthodontic treatment as a boon to make their smiles better and are ready to undertake the treatment without much hesitation. 


\section{Source of funding}

None.

\section{Conflict of interest}

None.

\section{References}

1. Cunningham SJ, O'Brien C. Quality of life and orthodontics. Semin Orthod 2007;13(2):96-103.

2. Hans MG, Valiathan M. Bobbing for apples in the garden of Eden. Semin Orthod 2005;11:86-93.

3. Liua Z, Mc Grathb C, Ha"ggc U. The impact of malocclusion/ orthodontic treatment need on the quality of life: A systematic review. Angle Orthod 2009;79:585-91.

4. Hassan AH. Orthodontic treatment needs in the western region of Saudi Arabia: A research report. Head \& Face Medicine 2006;2:2.

5. Nabeel F. Talic Adverse effects of orthodontic treatment: A clinical perspective. Saudi Dent J 2011;23(2):55-59.

6. Baswaraj, K. Jayasudha, K. M. Kumarswamy, M. N. Padmini, B. Chandralekha, D. P. Shruthi. Dental students perception of orthodontic treatment. J Indian Assoc Public Health Dent 2016:13(1).

7. Riya Agrawal. Knowledge, attitude and perception of orthodontic treatment among dental students. Int J Dent Res 2018;6(1):3-5.

8. Disha D Kandi Nitin Gulve, Sheetal Patani, Amit Nehete, Hrushikesh Aphale, Pallavi More, Rashi Raunka. The Prevalence of Malocclusion in Dental Students and Reasons for Avoiding Orthodontic Treatment. Int J Oral Health Med Res 2016;(2):52395-7387.

How to cite this article: Sharmila $M$, Rajakumar $P$, Vivekanandan U, Shivani R, Gopalakrishnan S, Gomathi GD. Attitude of dental interns with malocclusion towards seeking orthodontic treatment. Int Dent J Student Res 2019;7(4):107-12. 